\title{
Astrogliopathology in the infectious insults of the brain
}

DOI:

10.1016/j.neulet.2018.08.003

\section{Document Version}

Accepted author manuscript

Link to publication record in Manchester Research Explorer

\section{Citation for published version (APA):}

Zorec, R., Avši Zupanc, T., \& Verkhratsky, A. (2019). Astrogliopathology in the infectious insults of the brain. Neuroscience letters, 689. https://doi.org/10.1016/j.neulet.2018.08.003

\section{Published in:}

Neuroscience letters

\section{Citing this paper}

Please note that where the full-text provided on Manchester Research Explorer is the Author Accepted Manuscript or Proof version this may differ from the final Published version. If citing, it is advised that you check and use the publisher's definitive version.

\section{General rights}

Copyright and moral rights for the publications made accessible in the Research Explorer are retained by the authors and/or other copyright owners and it is a condition of accessing publications that users recognise and abide by the legal requirements associated with these rights.

\section{Takedown policy}

If you believe that this document breaches copyright please refer to the University of Manchester's Takedown Procedures [http://man.ac.uk/04Y6Bo] or contact uml.scholarlycommunications@manchester.ac.uk providing relevant details, so we can investigate your claim.

\section{OPEN ACCESS}




\section{Accepted Manuscript}

Title: Astrogliopathology in the infectious insults of the brain

Authors: Robert Zorec, Tatjana Avšič Županc, Alexei

Verkhratsky

PII: $\quad$ S0304-3940(18)30533-0

DOI: $\quad$ https://doi.org/10.1016/j.neulet.2018.08.003

Reference: $\quad$ NSL 33738

To appear in: $\quad$ Neuroscience Letters

Received date: $\quad 15-7-2018$

Revised date: $\quad 3-8-2018$

Accepted date: $\quad 4-8-2018$

Please cite this article as: Zorec R, Avšič Županc T, Verkhratsky A, Astrogliopathology in the infectious insults of the brain, Neuroscience Letters (2018), https://doi.org/10.1016/j.neulet.2018.08.003

This is a PDF file of an unedited manuscript that has been accepted for publication. As a service to our customers we are providing this early version of the manuscript. The manuscript will undergo copyediting, typesetting, and review of the resulting proof before it is published in its final form. Please note that during the production process errors may be discovered which could affect the content, and all legal disclaimers that apply to the journal pertain. 


\title{
Astrogliopathology in the infectious insults of the brain
}

\author{
Robert Zorec ${ }^{1,2}$ Tatjana Avšič Županc ${ }^{3}$ \& Alexei Verkhratsky $y^{1,2,4,5}$
}

${ }^{1}$ University of Ljubljana, Institute of Pathophysiology, Laboratory of Neuroendocrinology and Molecular Cell Physiology, Zaloska cesta 4; SI-1000, Ljubljana, Slovenia;

${ }^{2}$ Celica, BIOMEDICAL, Technology Park 24, 1000 Ljubljana, Slovenia,

${ }^{3}$ Institute of Microbiology and Immunology, Faculty of Medicine, University of Ljubljana, Zaloška 4, 1000 Ljubljana, Slovenia

${ }^{4}$ Faculty of Biology, Medicine and Health, The University of Manchester, Manchester, M13 9PT, UK; ${ }^{5}$ Achucarro Center for Neuroscience, IKERBASQUE, Basque Foundation for Science, 48011 Bilbao, Spain ; ${ }^{2}$ Center for Basic and Translational Neuroscience, Faculty of Health and Medical Sciences, University of Copenhagen, Copenhagen 2200, Denmark

Highlights

- Astrocytes, homeostatic cells of the central nervous system contribute to all neurological diseases.

- Astrogliopathlogy is represented by reactive astrogliosis, astrodegeneration with astroglial atrophy and loss of function and pathological remodelling.

- Astrocytes provide the defensive barrier against infectious agents but can be also the main target of neuroinfection.

- Asrocytes can provide a reservoir for proliferation of infectious agents.

\section{Abstract}

Astroglia, a heterogeneous type of neuroglia, play key homeostatic functions in the central nervous system (CNS) and represent an important defence system. Impaired homeostatic capacity of astrocytes manifests in diseases and this is mirrored in various astrocyte-based pathological features including reactive astrogliosis, astrodegeneration with astroglial atrophy and pathological remodelling of astrocytes. All of these manifestations are most prominently associated with infectious insults, mediated by bacteria, protozoa and viruses. Here we focus into neurotropic viruses such as tick-borne encephalitis (TBEV) and Zika virus (ZIKV), both belonging to 
Flaviviridae and both causing severe neurological impairments. We argue that astrocytes provide a route through which neurotropic infectious agents attack the CNS, since they are anatomically associated with the blood-brain barrier and exhibit aerobic glycolysis, a metabolic specialization of highly morphologically dynamic cells, which may provide a suitable metabolic milieu for proliferation of infectious agents, including viral bodies.

\section{Abbreviations}

BBB: blood-brain barrier; CNS: Central nervous system; CXCL-1, CXCL-10: chemokine ligand 1, 10; CVO: circumventricular organs; GFAP: glial fibrillary acidic protein; IL-6, IL-8: interleukin-6,8; TNF- $\alpha$ : tumour necrosis factor $\alpha$; STAT1: signal transducer and activator of transcription 1 ; TBEV: tick-borne encephalitis virus; ZIKV: Zika virus.

Keywords: Astroglia; Neuroinfection; CNS homeostasis; Zika virus; Tick-borne encephalitis virus 


\section{Astrocytes: Wardens and guarantors of the brain}

The function of the brain as an organ is determined by a complex system of cellular networks responsible for neural tissue homeostasis, which includes defence against exogenous pathogens and infectious agents. These defensive systems are represented by blood-brain barrier (BBB) formed by endothelial cells and pericytes and by neuroglia, consisting of microglia and macroglia. The latter group includes oligodendrocytes which myelinate and support axons and astroglia, highly morphologically heterogeneous cells, that act as key homeostatic elements of the CNS; in particular astrocytes control ionic balance (ionostasis), neurotransmitter turnover, energy balance and synaptic connectivity [112]. Evolutionary specialisation of neural cells resulted in division of functions, with majority of homeostatic molecular cascades confined to astroglia, while neurones express proteins needed for electrical excitation (i.e. the triggering action potentials and their propagation along axons), fast neurotransmitter release and synaptic plasticity [111]. Perisynaptic processes of protoplasmic astrocytes cover substantial proportion of (mostly excitatory) synapses throughout the CNS and form the synaptic cradle, which is fundamentally important for homeostatic control of neurotransmission [110]. These astroglial perisynaptic membranes contain $\mathrm{Na}^{+} / \mathrm{K}^{+}$pumps and inward rectifier $\mathrm{K}_{\text {ir }} 4.1$ channels, which control local $\mathrm{K}^{+}$ buffering and $\mathrm{K}^{+}$turnover, as well as high densities of solute carrier transporters that provide for uptake of glutamate, release of glutamine, secretion of reactive oxygen species scavengers and regulation of $\mathrm{pH}[87,110]$. The glutamate(GABA)-glutamine shuttle is imperative for maintenance of neurotransmission, because neurones cannot synthesise glutamate de novo and fully rely on astroglia for supply of glutamate precursor glutamine [41]. In addition astroglial cradle controls synaptogenesis through release of numerous trophic factors such as trombospondins, glypicans or hevins, and is involved in synaptic extinction [4, 27]. Moreover, astrocytes are central storage elements for glycogen $[43,57]$ and are the key site of cholesterols synthesis in the CNS, this cholesterol being ultimately required for synapse formation and remodelling [61].

A single protoplasmic astrocyte in human cortex establishes contacts with up to 2 million of synapses and hence astrocytes are capable of integrating information from multiple neuronal inputs thus tuning astroglial homeostatic cascades to the demands of neuronal networks [72, 113]. Astrocytes establish contacts with brain vasculature through endfeet formed by astroglial perivascular processes; these endfeet contribute to local control of capillaries constriction thereby linking neuronal activity to the blood flow (the phenomenon of functional hyperaemia). Astrocytes are secretory cells of the CNS being able to release 200 molecules from neuromodulators to hormones and trophic factors [109] into the extracellular space, where convective movement distributes them throughout the neural tissue; a mode of action similar to that present in the endocrine system, therefore these cells were termed gliocrine [107]. Finally, astroglial cells are an important part of brain defence system, through both homeostatic response and disease and context-specific astrogliotic remodelling which is of paramount importance for neuropathology [77].

\section{Types of astrolgiopathology: an overview}

Although the pathological potential of glial cells has been widely recognised in $19^{\text {th }}$ century $[2,5$, $6,45,71]$, the principles of astrogliopathology and the fundamental role of neuroglia in neurological diseases have been defined only in a recent decade $[12,29,30,32,77,85,96,97$, 
$106,115,116,118,119]$. Astrogliopathic changes are classified into (i) reactive (astro)gliosis; (ii) astrodegeneration with astroglial atrophy and loss of function and (iii) pathological remodelling of astrocytes [77, 108, 119].

Reactive gliosis is the most studied and most appreciated type of astrogliopathy, which is manifested in many neurological conditions. Reactive astrogliosis is an evolutionary conserved complex remodelling of astroglial biochemistry, morphology and function essentially aimed at neuroprotection and defence of neural tissue [12, 77, 96, 97]. Instigation of astrogliotic response results in multiple reactive phenotypes that differ depending on the specific disease context and display distinct changes in gene expression, morphology and physiology [56, 76, 77, 122]. Reactive astrocytes provide for neuroprotection and trophic support of stressed nervous tissue, isolate damaged area through formation of astroglia scar, they are instrumental for recovery of the compromised $\mathrm{BBB}$ and finally reactive astrocytes support post-lesion remodelling and regeneration of the nervous tissue.

In many neurological conditions the primary astrogliopathology emerges in a form of astrodegeneration with astroglial atrophy and loss of function. Particularly important are failures of astroglial homeostatic capabilities, represented for example by deficient uptake of glutamate (which leads to excitotoxicity) or defects in extracellular $\mathrm{K}^{+}$buffering. Astroglial atrophy and astrodegeneration are prominent in major neuropsychiatric diseases, in toxic encephalopathies such as Wernicke encephalopathy or hepatic encephalopathy, in addictive disorders and in neurodegenerative disorders such as for example amyotrophic lateral sclerosis or Alzheimer's disease $[22,23,46,66,73,83,85,90,91,94,114,117,120]$.

The third type of astrogliopathology is represented by pathological remodelling of astroglial cells, when they acquire specific properties that facilitate and even drive pathological process. The most notable example of astroglial pathological remodelling is observed in Alexander disease caused by expression of sporadically mutated glial fibrillary acidic protein (GFAP), a cytoskeletal intermediate filament. This causes yet uncharacterised changes in astroglial function, likely involving a perturbed vesicle network system which result in severe damage to the white matter and leucomalacia $[53,65,123]$.

\section{Astrocytes in infectious diseases of the brain}

Astrocytes contribute to the infectious lesions of the brain in several ways. First and foremost they are the part of brain defence system and inner part of the BBB. Of note, brain areas of the circumventricular organs (CVOs) are highly vascularised, lacking a tight (endothelial) BBB. These structures include the subfornical organ, the organum vasculosum of the lamina terminalis and the area postrema.. The circumventricular organs (CVOs) are atypical brain structures lining the third and fourth ventricles, which exist in the brains of all vertebrates. They play a role in regulating body homeostasis based on blood-brain communication [37]. In the CVOs, the bloodbrain interface is formed by a rich capillary plexus harbouring a fenestrated endothelium [20] and lacking tight junction complexes in the endothelial cells [92]. Infectious agents cross the BBB in several ways (including paracellular route, transcytosis, receptor hijacking or infected leukocytes, the Trojan horse route $[21,49])$ after entering brain parenchyma are met by astroglial cells. Astrocytes express several receptors for pathogen-associated molecular patterns, and can possibly recognise various bacterial agents. At the same time astrocytes are targets of infectious 
agents; and after being infected astroglial cells may either mount astrogliotic defensive response, which is associated with neuroinflammation [40], or undergo pathological remodelling which may mediate pathological progression or even become the reservoir for infection.

\subsection{Bacterial infection of astroglia}

Many bacteria which cause brain infection interact with astroglia and trigger astroglial reactivity. Activation of astrocytes was observed, for example, in pneumococcal meningitis caused by Streptococcus pneumoniae [44] or Neisseria meningitides [17]. Astroglial reactivity was also induced by infection with Borrelia burgdorferi, the Lyme disease spirochete which does not produce lipopolysaccharide [26, 84]; this activation of astroglia resulted in significant increase in secretion of pro-inflammatory factors such as in IL-6, TNF- $\alpha$, IL-8, CXCL-1, and CXCL-10 [11]. Astroglial reactivity in the context of brain infection has clear defensive value, because suppression of astrogliotic response, for example in mice lacking GFAP, exacerbates the spread of infection and neurological damage [99]. Similarly, genetic deletion of NK-1R receptor activated by Substance $P$ reduced astrogliosis and limited inflammatory response to $N$. meningitidis [17]. Brain infection with Staphylococcus aureus results in a down-regulaton of astroglial synthesis of connexins and hence in a decrease of astroglial syncytial connectivity between cells surrounding the infection foci [28]. This decrease in gap junctional connectivity may reflect a defensive reaction that limits the spread of the infection.

\subsection{Ptotozoan infection of astrocytes}

The Toxoplasma gondii, an obligate intracellular, parasitic alveolate that causes the disease toxoplasmosis, seems to have an affinity to astroglia (although see [13], and tachyzoites, the asexual stage microorganism growth, were identified in the astroglial cells [101]; activation of astrocytes and up-regulation of cytokine production however inhibits tachyzoites. Failure of this inhibition, for example in astrocytes lacking gp130 (a protein of IL-6 signalling pathway) results in rapid development of lethal necrotising toxoplasma encephalitis [121]. Parasite replication seems also to be under control of signal transducer and activator of transcription 1 (STAT1) and genetic deletion of this factor facilitates uncontrolled spread of $T$. gondii infection [42]. Infection of astrocytes with $T$. gondii may result in pathological remodelling of the former; infected astrocytes start to produce excessive amount of kynurenic acid, which interacts with glutamate and acetylcholine receptors, thus casing abnormal neurotransmission which may lead to schizophrenia [93]. Astrocytes also contribute to cerebral malaria caused by infection with Plasmodium falciparum. In the early stages of infection astrocytes become reactive and increase secretion of TNF- $\alpha$ [63], whereas at late and terminal stages of cerebra malaris the loss of astrocytes and possible loss of their protective function occurs, which may contribute to the BBB failure and spread of infection $[62,63]$.

\subsection{Viral infections of the brain: Special case of flavivirus TBEV and ZIKA viruses}

A virus is considered to be neuroinvasive when it can enter the nervous system and neurovirulent when it is capable of causing disease within the nervous system. For example, poliovirus is highly neurovirulent but weakly neuroinvasive; rabies virus, also highly neurovirulent, requires a trauma (usually a bite by an animal) for neuroinvasiveness. Many viruses use arthropods, such as ticks and mosquitoes, to enter the human body, and then invade the CNS via the blood system. 
The brain infection by arthropod-borne viruses is best presented by the case of Zika virus (ZIKV) epidemic in the Central and South Americas, as this virus causes a prominent neurodevelopmental defect, microcephaly (under-development of the cerebral cortex in newborn babies from infected mothers [67]). Moreover, in adults ZIKV may also induce neurologic impairments known as the Guillain-Barré syndrome, characterized by a rapid-onset of muscle weakness [51, 100]. How ZIKV causes these effects, especially in the adults, where clinical manifestations can occur within hours, remains unclear, although this may reflect a highly efficient neuroinvasiveness of this flavivirus.

\subsubsection{Virus entry and cytoplasmic transport}

An imperative step in the cascade of complex events in virus neuroinvasion is that the virus enters the CNS, hence it must cross the BBB, which represents a barrier of CNS tissue preventing the direct ingress of viruses circulating in the blood [9,58]. The parenchymal portion of BBB is represented by astroglial endfeet, which provide an almost complete coverage of the intracranial blood vessels. At the same time astrocytes are not in contact with blood vessels only, but also enwrap synapses, hence they are intermediates and integrators of a neurovascular unit $[7,14]$.

Both ZIKV and the tick-borne encephalitis virus (TBEV), belong to the family of Flaviviridae [67, $88]$, a human pathogen that causes neuroinfections in Euroasia [19, 36, 58], enters the astrocytes by endocytosis [78] to cause the neuroinfection. Upon the entry of TBEV into astrocytes there is a preceding binding to a receptor, involving many mechanisms, including the interaction with heparan sulfate (HS), a glycosaminoglycan $[50,52,58,59]$. Endocytosis appears to be common mechanism of neurotropic virus brain infection, since human immunodeficiency virus 1 (HIV-1) enters astroglia by endocytosis as well, albeit the fate of HIV-1 virus seems to be linked with its destruction in the endolysosomes [16]. Some of the HIV-1 virus parts, such as the protein Nef can be propagated to neighbouring cells via vesicle-like structures, and this process is inhibited by elevated cytosolic calcium levels, $\left[\mathrm{Ca}^{2+}\right]_{\mathrm{i}}[98]$, which contrasts to the case where elevated $\left[\mathrm{Ca}^{2+}\right]_{i}$ stimulates vesicle-based secretion [47, 60, 95]. The internalisation of TBEV particles into astrocytes [78] is consistent with the clathrin-dependent endocytotic entry known for several members of Flaviviridae family including West Nile virus (WNV) [19], Dengue virus [3, 69], Hepatitis C virus [10] and Bovine Viral Diarrhoea virus (BVDV) [38]. Localization of TBEV in late endosomes/lysosomes is similarly consistent with other flaviviruses: BVDV, [38]; WNV, [18]; DILlabelled dengue virus, [69]. Therefore, ZIKV may use a similar strategy to enter the human brain via astrocytes, as it is depicted in Fig. 1, which reveals ZIKV particles, characterized by structures of less than $50 \mathrm{~nm}$ in diameter, with an electron-dense core, present in an electron-lucent most likely endosomal compartment.

At least in rodent brain, the infection by TBEV has no detrimental effect on astroglial viability and hence rat astrocytes likely represent a reservoir for TBEV from where further infection and reinfection can occur [78]. Why astroglia presents a suitable environment for TBEV and other proliferating microorganisms is discussed below.

\subsubsection{Viral infection and cytoplasmic vesicular traffic}


Once within a cell virus particles can traffic to different parts in the cytoplasm. In astroglia the TBEV uses the endosomal system for the spread within the cytoplasm and this was monitored in real-time [78]. On Fig. 2, TBEV, labelled by a fluorescent marker DiD, associates with early endosomes (co-localization with early endosome antigen 1, EEA1). If time after post-infection is prolonged, the DiD-TBEV particles also associate with the lysosomal associated membrane protein 1 (LAMP1) marker. These structures are not stationary, but exhibit intracellular mobility, which is similar to that described for secretory vesicles [80]. These compartments may also deliver receptors and transporters to the plasma membrane [81]. Once TBEV is endocytosed, the TBEVpositive organelles may either enter the directional and/or the non-directional mode of mobility in living cells. Directional mobility is considered to be driven by protein motors carrying vesicles along the cytoskeletal elements, including microtubules, actin and intermediate filaments, such as the astroglia-specific GFAP [79]. On the other hand, vesicles exhibiting non-directional mobility are exposed to randomness determined by free diffusion [80]. As a function of the post-infection time, which resulted in increased number of TBEV particles per astrocytes, there was also a pronounced increase in TBEV particle mobility [78].

Changes in virus-particle cytoplasmic traffic may reflect the virus-mediated cell function alterations. Morphological developmental defects, such as microcephally in the case of ZIKV infection [67], may be due to virus-impaired cell shape mechanisms. This is possible since changes in cytoskeleton were reported for several viral infections including herpes virus, [35], TBEV, [89]); the TBEV dependent alteration of astroglial cytoskeleton was also reported; this alterations however, did not affect the viability of rat astrocytes [78]. Whether this is also the case in the TBEV- and ZIKV-infected human astrocytes remains to be investigated.

Similarly to the infiltration of TBEV, endocytosis was recently confirmed to be the mechanism of ZIKV infection of astrocytes and microglia [64]. Here a protein (AxI), a member of the Tyro3 AxI Mer (TAM) family, was identified. The membrane protein Axl, is involved in the removal of apoptotic cells, regulating innate immunity [55]. Abundant expression of Axl in glial cells, and its absence in neural progenitor cells, indicates a cellular astroglial tropism for ZIKV infection [64]. Additional experiments will have to be conducted, ideally on human cells, to establish the mechanism of neurovirulence of flaviviruses, including ZIKV and their putative preferential association with astroglia and the specialized form astroglia, radial glia.

These latter cells are essential in shaping the development of the human neocortex, through the activity of the brainstem nucleus Locus coeruleus (LC) [31]. The LC neurones release noradrenaline, which in astroglia elevates cytosolic $\mathrm{Ca}^{2+}[8,25,48,74,75]$, elevated $\mathrm{Ca}^{2+}$ in turn stimulates astroglial aerobic glycolysis, resuting in an increase in cytosolic glucose concentration $[82,105]$, leading to the production of L-lactate $[24,43,105]$. Astroglial excitability is linked to many effector mechanisms including that mediated by L-lactate, that also serves as an extracellular signalling molecule acting through the L-lactate receptor GPR81 or HCAR1 [54, 68]. At least in astrocytes L-lactate also acts through a yet unidentified L-lactate receptor [105]. The increased production of astroglial L-lactate may result in elevated levels of extracellular L-lactate concentration; thus latter may reach (in humans) $5 \mathrm{mM}$ being much higher than in the blood plasma at the rest [1]. Elevated extracellular levels of L-lactate feed-back to the LC neurones in a 
manner, which then releases even more noradrenaline [102], an interesting glio-neuronal communication where L-lactate serves as extracellular signalling molecule.

As already highlighted, extracellular L-lactate may have many signalling functions, including playing a role in angiogenesis linked to metabolism [68], to be neuroprotective against various types of brain damage [15] and is required for cancer cell survival [86]. Moreover, the L-lactate mediated "metabolic excitability", where extracellular L-lactate enhances astroglial aerobic glycolysis, via a yet unidentified receptor [105], may contribute to the maintenance of the Llactate gradient between the brain interstitium and the plasma [1]. This gradient may also be linked to the neuroinvasiveness and neurovirulence.

\subsubsection{Astrocytes as a reservoir for proliferation of infectious agents}

Why do astrocytes present a favourable milieu for viral and other microorganism's infections? To address this question, let us consider that in addition to transmission of ZIKV by mosquitoes, there is evidence for human-to-human sexual ZIKV transmission, as studied in a special case of an infected male [70]. This means that ZIKV has to be present in the cells associated with spermatogenesis. Indeed, it was reported that ZIKV is present in the testes of mice in cells that are highly active in cell division including spermatocytes, Sertoli cells and spermatogonia [33]. For survival, spermatogonial stem cells, exhibiting dynamic proliferation, require an environment that favours glycolysis [39]. Why is glycolysis important for proliferation? Eukaryotic and prokaryotic cell division requires building blocks and material for making new cells, protozoa, bacteria or viruses, therefore it is essential that such intermediates are available, and glycolysis may be a favourable environment for dynamic replication.

As in the case of ZIKV-infected testes [33], where glycolytic environment favours spermatogonial cell division [39], it is likely, that astrocytes provide a favourable environment to support replication of viruses, since they exhibit a special adaptation of glycolysis. Aerobic glycolysis exists in rapidly dividing cells and in cells undergoing plastic morphological changes, despite the presence of adequate levels of oxygen, a phenomenon known as "the Warburg effect" [104], typically present in cancer cells. This metabolic specialisation is also present in astroglia. Although it is not very efficient in producing ATP, it generates biosynthetic intermediates, an essential advantage for developing and growing tissues [103] and supporting the proliferation of infective agents. Aerobic glycolysis, primarily taking place in astrocytes in the CNS, is operative during neurodevelopment and even in adulthood in some areas of the CNS [34]. Therefore, this property of astrocytes may be a reason of why bacteria, protozoa and viruses exhibit a preference for astroglia. In addition, ZIKV-mediated microcephally, may be a result of impaired radial glia, critical for neurogenesis and the development of the neocortical cell stratification. In addition these cells are also a cell type that generates a favourable environment for virus infection. This in turn affects the cytoskeleton and astroglial cell polarity and shape, which is detrimental for the radial glia playing a guiding role in the neocortex development, when the foetal brain is infected by ZIKV.

\section{Conclusions}

This short review aimed to highlight that astrogliopathology, a recently acknowledged and growing field, links the evolution of neurological diseases with morphology and function of astroglia. Pathological potential of astrocytes needs to be investigated in much more detail to 
understand the processes that are impaired during homeostatic CNS failure. This is essential for the development of new drugs that interfere with these pathobiological processes. Since infections of the nervous system with two main entry points into the CNS (blood and cerebrospinal fluid, Fig. 3), represent an important traditional aspect of neurological diseases, we here focused on bacterial, protozoan and viral infections and brief how astrocytes deal with these pathogens. Specifically, we present the special cases of tick-borne encephalitis and Zika viruses and their interaction with astrocytes, and argue that astrocytic glycolytic milieu is a favourable environment for infectious agents.

\section{Acknowledgements}

This work was supported by grants P3 310, J3 6790, J3 6789 and J3 7605 from the Slovenian Research Agency (ARRS), CipKeBip, COST Action BM1002, EU COST Action CM1207 - GLISTEN (to RZ). 


\section{References}

[1] W.M. Abi-Saab, D.G. Maggs, T. Jones, R. Jacob, V. Srihari, J. Thompson, D. Kerr, P. Leone, J.H. Krystal, D.D. Spencer, M.J. During, R.S. Sherwin, Striking differences in glucose and lactate levels between brain extracellular fluid and plasma in conscious human subjects: effects of hyperglycemia and hypoglycemia, J Cereb Blood Flow Metab 22 (2002) 271279.

[2] N. Achucarro, De l'évulotion de la névroglie, et spécialement de ses relations avec I'appareil vasculaire, Trab Lab Invest Biol (Madrid) 13 (1915) 169-212.

[3] E.G. Acosta, V. Castilla, E.B. Damonte, Functional entry of dengue virus into Aedes albopictus mosquito cells is dependent on clathrin-mediated endocytosis, J Gen Virol 89 (2008) 474-484.

[4] N.J. Allen, M.L. Bennett, L.C. Foo, G.X. Wang, C. Chakraborty, S.J. Smith, B.A. Barres, Astrocyte glypicans 4 and 6 promote formation of excitatory synapses via GluA1 AMPA receptors, Nature 486 (2012) 410-414.

[5] A. Alzheimer, Beiträge zur Kenntnis der pathologischen Neuroglia und ihrer Beziehungen zu den Abbauvorgängen im Nervengewebe. Histologische und Histopathologische Arbeiten über die Grosshirnrinde mit besonderer Berücksichtigung der pathologischen Anatomie der Geisteskrankheiten Vol. 3. Band 3. Heft, Verlag von Gustav Fischer Jena, 1910.

[6] W.L. Andriezen, The neuroglia elements of the brain, Br. Med. J 2 (1893) 227-230.

[7] D. Attwell, A.M. Buchan, S. Charpak, M. Lauritzen, B.A. Macvicar, E.A. Newman, Glial and neuronal control of brain blood flow, Nature 468 (2010) 232-243.

[8] L.K. Bekar, W. He, M. Nedergaard, Locus coeruleus alpha-adrenergic-mediated activation of cortical astrocytes in vivo, Cereb Cortex 18 (2008) 2789-2795.

[9] J. Bernacki, A. Dobrowolska, K. Nierwinska, A. Malecki, Physiology and pharmacological role of the blood-brain barrier, Pharmacol Rep 60 (2008) 600-622.

[10] E. Blanchard, S. Belouzard, L. Goueslain, T. Wakita, J. Dubuisson, C. Wychowski, Y. Rouille, Hepatitis $C$ virus entry depends on clathrin-mediated endocytosis, J Virol 80 (2006) 6964-6972.

[11] C.A. Brissette, E.D. Kees, M.M. Burke, R.A. Gaultney, A.M. Floden, J.A. Watt, The multifaceted responses of primary human astrocytes and brain microvascular endothelial cells to the Lyme disease spirochete, Borrelia burgdorferi, ASN Neuro 5 (2013) 221-229.

[12] J.E. Burda, M.V. Sofroniew, Reactive gliosis and the multicellular response to CNS damage and disease, Neuron 81 (2014) 229-248. 
[13] C.M. Cabral, S. Tuladhar, H.K. Dietrich, E. Nguyen, W.R. MacDonald, T. Trivedi, A. Devineni, A.A. Koshy, Neurons are the Primary Target Cell for the Brain-Tropic Intracellular Parasite Toxoplasma gondii, PLoS Pathog 12 (2016) e1005447.

[14] G. Carmignoto, M. Gomez-Gonzalo, The contribution of astrocyte signalling to neurovascular coupling, Brain Res Rev 63 (2010) 138-148.

[15] X. Castillo, K. Rosafio, M.T. Wyss, K. Drandarov, A. Buck, L. Pellerin, B. Weber, L. Hirt, A probable dual mode of action for both L- and D-lactate neuroprotection in cerebral ischemia, J Cereb Blood Flow Metab 35 (2015) 1561-1569.

[16] A. Chauhan, A. Tikoo, J. Patel, A.M. Abdullah, HIV-1 endocytosis in astrocytes: a kiss of death or survival of the fittest?, Neurosci Res 88 (2014) 16-22.

[17] V.S. Chauhan, D.G. Sterka, Jr., D.L. Gray, K.L. Bost, I. Marriott, Neurogenic exacerbation of microglial and astrocyte responses to Neisseria meningitidis and Borrelia burgdorferi, J Immunol 180 (2008) 8241-8249.

[18] J.J. Chu, P.W. Leong, M.L. Ng, Analysis of the endocytic pathway mediating the infectious entry of mosquito-borne flavivirus West Nile into Aedes albopictus mosquito (C6/36) cells, Virology 349 (2006) 463-475.

[19] J.J. Chu, M.L. Ng, Infectious entry of West Nile virus occurs through a clathrin-mediated endocytic pathway, J Virol 78 (2004) 10543-10555.

[20] P. Ciofi, The arcuate nucleus as a circumventricular organ in the mouse, Neurosci Lett 487 (2011) 187-190.

[21] V. Combes, G.J. Guillemin, T. Chan-Ling, N.H. Hunt, G.E. Grau, The crossroads of neuroinflammation in infectious diseases: endothelial cells and astrocytes, Trends Parasitol 28 (2012) 311-319.

[22] D. Cotter, D. Mackay, G. Chana, C. Beasley, S. Landau, I.P. Everall, Reduced neuronal size and glial cell density in area 9 of the dorsolateral prefrontal cortex in subjects with major depressive disorder, Cereb Cortex 12 (2002) 386-394.

[23] B. Czeh, B. Di Benedetto, Antidepressants act directly on astrocytes: evidences and functional consequences, Eur Neuropsychopharmacol 23 (2013) 171-185.

[24] G.A. Dienel, N.F. Cruz, Aerobic glycolysis during brain activation: adrenergic regulation and influence of norepinephrine on astrocytic metabolism, J Neurochem 138 (2016) 1452.

[25] F. Ding, J. O'Donnell, A.S. Thrane, D. Zeppenfeld, H. Kang, L. Xie, F. Wang, M. Nedergaard, $\alpha_{1}$-Adrenergic receptors mediate coordinated $\mathrm{Ca}^{2+}$ signaling of cortical astrocytes in awake, behaving mice, Cell Calcium 54 (2013) 387-394.

[26] L. Dotevall, L.E. Rosengren, L. Hagberg, Increased cerebrospinal fluid levels of glial fibrillary acidic protein (GFAp) in Lyme neuroborreliosis, Infection 24 (1996) 125-129. 
[27] C. Eroglu, B.A. Barres, Regulation of synaptic connectivity by glia, Nature 468 (2010) 223-231.

[28] N. Esen, D. Shuffield, M.M. Syed, T. Kielian, Modulation of connexin expression and gap junction communication in astrocytes by the gram-positive bacterium S. aureus, Glia 55 (2007) 104-117.

[29] I. Ferrer, Astrogliopathy in tauopathies, Neuroglia 1 (2018) 10.

[30] I. Ferrer, Diversity of astroglial responses across human neurodegenerative disorders and brain aging, Brain Pathol 27 (2017) 645-674.

[31] S.L. Foote, F.E. Bloom, G. Aston-Jones, Nucleus locus ceruleus: new evidence of anatomical and physiological specificity, Physiol Rev 63 (1983) 844-914.

[32] C. Giaume, F. Kirchhoff, C. Matute, A. Reichenbach, A. Verkhratsky, Glia: the fulcrum of brain diseases, Cell Death Differ 14 (2007) 1324-1335.

[33] J. Govero, P. Esakky, S.M. Scheaffer, E. Fernandez, A. Drury, D.J. Platt, M.J. Gorman, J.M. Richner, E.A. Caine, V. Salazar, K.H. Moley, M.S. Diamond, Zika virus infection damages the testes in mice, Nature 540 (2016) 438-442.

[34] M.S. Goyal, M. Hawrylycz, J.A. Miller, A.Z. Snyder, M.E. Raichle, Aerobic glycolysis in the human brain is associated with development and neotenous gene expression, Cell Metab 19 (2014) 49-57.

[35] W. Greene, S.J. Gao, Actin dynamics regulate multiple endosomal steps during Kaposi's sarcoma-associated herpesvirus entry and trafficking in endothelial cells, PLoS Pathog 5 (2009) e1000512.

[36] T.S. Gritsun, V.A. Lashkevich, E.A. Gould, Tick-borne encephalitis, Antiviral Res 57 (2003) 129-146.

[37] P.M. Gross, A. Weindl, Peering through the windows of the brain, J Cereb Blood Flow Metab 7 (1987) 663-672.

[38] B. Grummer, S. Grotha, I. Greiser-Wilke, Bovine viral diarrhoea virus is internalized by clathrin-dependent receptor-mediated endocytosis, J Vet Med B Infect Dis Vet Public Health 51 (2004) 427-432.

[39] A.R. Helsel, M.J. Oatley, J.M. Oatley, Glycolysis-Optimized Conditions Enhance Maintenance of Regenerative Integrity in Mouse Spermatogonial Stem Cells during Long-Term Culture, Stem Cell Reports 8 (2017) 1430-1441.

[40] M.T. Heneka, M.J. Carson, J. El Khoury, G.E. Landreth, F. Brosseron, D.L. Feinstein, A.H. Jacobs, T. Wyss-Coray, J. Vitorica, R.M. Ransohoff, K. Herrup, S.A. Frautschy, B. Finsen, G.C. Brown, A. Verkhratsky, K. Yamanaka, J. Koistinaho, E. Latz, A. Halle, G.C. Petzold, T. Town, D. Morgan, M.L. Shinohara, V.H. Perry, C. Holmes, N.G. Bazan, D.J. Brooks, S. Hunot, B. Joseph, N. Deigendesch, O. Garaschuk, E. Boddeke, C.A. Dinarello, J.C. 
Breitner, G.M. Cole, D.T. Golenbock, M.P. Kummer, Neuroinflammation in Alzheimer's disease, Lancet Neurol 14 (2015) 388-405.

[41] L. Hertz, The glutamate-glutamine (GABA) cycle: importance of late postnatal development and potential reciprocal interactions between biosynthesis and degradation, Front Endocrinol (Lausanne) 4 (2013) 59.

[42] S. Hidano, L.M. Randall, L. Dawson, H.K. Dietrich, C. Konradt, P.J. Klover, B. John, T.H. Harris, Q. Fang, B. Turek, T. Kobayashi, L. Hennighausen, D.P. Beiting, A.A. Koshy, C.A. Hunter, STAT1 Signaling in Astrocytes Is Essential for Control of Infection in the Central Nervous System, MBio 7 (2016).

[43] A. Horvat, N. Vardjan, R. Zorec, Targeting Astrocytes for Treating Neurological Disorders: Carbon Monoxide and Noradrenaline-Induced Increase in Lactate, Curr Pharm Des 23 (2017) 4969-4978.

[44] F. lovino, C.J. Orihuela, H.E. Moorlag, G. Molema, J.J. Bijlsma, Interactions between blood-borne Streptococcus pneumoniae and the blood-brain barrier preceding meningitis, PLoS One 8 (2013) e68408.

[45] M. Jastrowitz, Encephalitis und Myelitis des ersten Kindersalters, Arch $\mathrm{f}$ Psychiat 2 (1870) 389-414.

[46] V.C. Jones, R. Atkinson-Dell, A. Verkhratsky, L. Mohamet, Aberrant iPSC-derived human astrocytes in Alzheimer's disease, Cell Death Dis 8 (2017) e2696.

[47] B. Katz, Quantal mechanism of neural transmitter release, Science 173 (1971) 123-126.

[48] S. Kirischuk, S. Tuschick, A. Verkhratsky, H. Kettenmann, Calcium signalling in mouse Bergmann glial cells mediated by $\alpha_{1}$-adrenoreceptors and $\mathrm{H}_{1}$ histamine receptors, Eur J Neurosci 8 (1996) 1198-1208.

[49] R.S. Klein, C.A. Hunter, Protective and Pathological Immunity during Central Nervous System Infections, Immunity 46 (2017) 891-909.

[50] L.I. Kozlovskaya, D.I. Osolodkin, A.S. Shevtsova, L. Romanova, Y.V. Rogova, T.I. Dzhivanian, V.N. Lyapustin, G.P. Pivanova, A.P. Gmyl, V.A. Palyulin, G.G. Karganova, GAG-binding variants of tick-borne encephalitis virus, Virology 398 (2010) 262-272.

[51] F. Krauer, M. Riesen, L. Reveiz, O.T. Oladapo, R. Martinez-Vega, T.V. Porgo, A. Haefliger, N.J. Broutet, N. Low, W.H.O.Z.C.W. Group, Zika Virus Infection as a Cause of Congenital Brain Abnormalities and Guillain-Barre Syndrome: Systematic Review, PLoS Med 14 (2017) e1002203.

[52] H. Kroschewski, S.L. Allison, F.X. Heinz, C.W. Mandl, Role of heparan sulfate for attachment and entry of tick-borne encephalitis virus, Virology 308 (2003) 92-100.

[53] A. Lanciotti, M.S. Brignone, E. Bertini, T.C. Petrucci, F. Aloisi, E. Ambrosini, Astrocytes: Emerging stars in leukodystrophy pathogenesis, Transl Neurosci 4 (2013). 
[54] K.H. Lauritzen, C. Morland, M. Puchades, S. Holm-Hansen, E.M. Hagelin, F. Lauritzen, H. Attramadal, J. Storm-Mathisen, A. Gjedde, L.H. Bergersen, Lactate receptor sites link neurotransmission, neurovascular coupling, and brain energy metabolism, Cereb Cortex 24 (2014) 2784-2795.

[55] G. Lemke, C.V. Rothlin, Immunobiology of the TAM receptors, Nat Rev Immunol 8 (2008) 327-336.

[56] S.A. Liddelow, B.A. Barres, Reactive Astrocytes: Production, Function, and Therapeutic Potential, Immunity 46 (2017) 957-967.

[57] P.J. Magistretti, I. Allaman, Lactate in the brain: from metabolic end-product to signalling molecule, Nat Rev Neurosci 19 (2018) 235-249.

[58] C.W. Mandl, Steps of the tick-borne encephalitis virus replication cycle that affect neuropathogenesis, Virus Res 111 (2005) 161-174.

[59] C.W. Mandl, H. Kroschewski, S.L. Allison, R. Kofler, H. Holzmann, T. Meixner, F.X. Heinz, Adaptation of tick-borne encephalitis virus to BHK-21 cells results in the formation of multiple heparan sulfate binding sites in the envelope protein and attenuation in vivo, J Virol 75 (2001) 5627-5637.

[60] W.T. Mason, S.R. Rawlings, P. Cobbett, S.K. Sikdar, R. Zorec, S.N. Akerman, C.D. Benham, M.J. Berridge, T. Cheek, R.B. Moreton, Control of secretion in anterior pituitary cells-linking ion channels, messengers and exocytosis, J Exp Biol 139 (1988) 287-316.

[61] D.H. Mauch, K. Nagler, S. Schumacher, C. Goritz, E.C. Muller, A. Otto, F.W. Pfrieger, CNS synaptogenesis promoted by glia-derived cholesterol, Science 294 (2001) 1354-1357.

[62] I.M. Medana, N.P. Day, T.T. Hien, N.T. Mai, D. Bethell, N.H. Phu, J. Farrar, M.M. Esiri, N.J. White, G.D. Turner, Axonal injury in cerebral malaria, Am J Pathol 160 (2002) 655-666.

[63] I.M. Medana, N.H. Hunt, T. Chan-Ling, Early activation of microglia in the pathogenesis of fatal murine cerebral malaria, Glia 19 (1997) 91-103.

[64] L. Meertens, A. Labeau, O. Dejarnac, S. Cipriani, L. Sinigaglia, L. Bonnet-Madin, T. Le Charpentier, M.L. Hafirassou, A. Zamborlini, V.M. Cao-Lormeau, M. Coulpier, D. Misse, N. Jouvenet, R. Tabibiazar, P. Gressens, O. Schwartz, A. Amara, AxI Mediates ZIKA Virus Entry in Human Glial Cells and Modulates Innate Immune Responses, Cell Rep 18 (2017) 324-333.

[65] A. Messing, M. Brenner, M.B. Feany, M. Nedergaard, J.E. Goldman, Alexander disease, J Neurosci 32 (2012) 5017-5023.

[66] J.J. Miguel-Hidalgo, The role of glial cells in drug abuse, Curr Drug Abuse Rev 2 (2009) 76-82.

[67] J. Mlakar, M. Korva, N. Tul, M. Popovic, M. Poljsak-Prijatelj, J. Mraz, M. Kolenc, K. Resman Rus, T. Vesnaver Vipotnik, V. Fabjan Vodusek, A. Vizjak, J. Pizem, M. Petrovec, T. 
Avsic Zupanc, Zika Virus Associated with Microcephaly, N Engl J Med 374 (2016) 951958.

[68] C. Morland, K.A. Andersson, O.P. Haugen, A. Hadzic, L. Kleppa, A. Gille, J.E. Rinholm, V. Palibrk, E.H. Diget, L.H. Kennedy, T. Stolen, E. Hennestad, O. Moldestad, Y. Cai, M. Puchades, S. Offermanns, K. Vervaeke, M. Bjoras, U. Wisloff, J. Storm-Mathisen, L.H. Bergersen, Exercise induces cerebral VEGF and angiogenesis via the lactate receptor HCAR1, Nat Commun 8 (2017) 15557.

[69] C. Mosso, I.J. Galvan-Mendoza, J.E. Ludert, R.M. del Angel, Endocytic pathway followed by dengue virus to infect the mosquito cell line C6/36 HT, Virology 378 (2008) 193-199.

[70] D. Musso, C. Roche, E. Robin, T. Nhan, A. Teissier, V.M. Cao-Lormeau, Potential sexual transmission of Zika virus, Emerg Infect Dis 21 (2015) 359-361.

[71] F. Nissl, Ueber einige Beziehungen zwischen Nervenzellerkrankungen und gliiSsen Erscheinungen bei verschiedenen Psychosen., 32: 1-2I., Arch. Psychiat 32 (1899) 1-21.

[72] N.A. Oberheim, S.A. Goldman, M. Nedergaard, Heterogeneity of astrocytic form and function, Methods Mol Biol 814 (2012) 23-45.

[73] M. Olabarria, H.N. Noristani, A. Verkhratsky, J.J. Rodriguez, Concomitant astroglial atrophy and astrogliosis in a triple transgenic animal model of Alzheimer's disease, Glia 58 (2010) 831-838.

[74] Y. Pankratov, U. Lalo, Role for astroglial $\alpha_{1}$-adrenoreceptors in gliotransmission and control of synaptic plasticity in the neocortex, Front Cell Neurosci 9 (2015) 230.

[75] M. Paukert, A. Agarwal, J. Cha, V.A. Doze, J.U. Kang, D.E. Bergles, Norepinephrine controls astroglial responsiveness to local circuit activity, Neuron 82 (2014) 1263-1270.

[76] M. Pekny, M. Pekna, Astrocyte reactivity and reactive astrogliosis: costs and benefits, Physiol Rev 94 (2014) 1077-1098.

[77] M. Pekny, M. Pekna, A. Messing, C. Steinhauser, J.M. Lee, V. Parpura, E.M. Hol, M.V. Sofroniew, A. Verkhratsky, Astrocytes: a central element in neurological diseases, Acta Neuropathol 131 (2016) 323-345.

[78] M. Potokar, M. Korva, J. Jorgacevski, T. Avsic-Zupanc, R. Zorec, Tick-borne encephalitis virus infects rat astrocytes but does not affect their viability, PLoS One 9 (2014) e86219.

[79] M. Potokar, M. Kreft, L. Li, J. Daniel Andersson, T. Pangrsic, H.H. Chowdhury, M. Pekny, R. Zorec, Cytoskeleton and vesicle mobility in astrocytes, Traffic 8 (2007) 12-20.

[80] M. Potokar, M. Kreft, T. Pangrsic, R. Zorec, Vesicle mobility studied in cultured astrocytes, Biochem Biophys Res Commun 329 (2005) 678-683.

[81] M. Potokar, M. Stenovec, J. Jorgacevski, T. Holen, M. Kreft, O.P. Ottersen, R. Zorec, Regulation of AQP4 surface expression via vesicle mobility in astrocytes, Glia 61 (2013) 917-928. 
[82] M. Prebil, N. Vardjan, J. Jensen, R. Zorec, M. Kreft, Dynamic monitoring of cytosolic glucose in single astrocytes, Glia 59 (2011) 903-913.

[83] G. Rajkowska, J.J. Miguel-Hidalgo, Z. Makkos, H. Meltzer, J. Overholser, C. Stockmeier, Layer-specific reductions in GFAP-reactive astroglia in the dorsolateral prefrontal cortex in schizophrenia, Schizophr Res 57 (2002) 127-138.

[84] G. Ramesh, A.L. Alvarez, E.D. Roberts, V.A. Dennis, B.L. Lasater, X. Alvarez, M.T. Philipp, Pathogenesis of Lyme neuroborreliosis: Borrelia burgdorferi lipoproteins induce both proliferation and apoptosis in rhesus monkey astrocytes, Eur J Immunol 33 (2003) 25392550.

[85] J.J. Rodriguez, A.M. Butt, E. Gardenal, V. Parpura, A. Verkhratsky, Complex and differential glial responses in Alzheimer's disease and ageing, Curr Alzheimer Res 13 (2016) 343-358.

[86] C.L. Roland, T. Arumugam, D. Deng, S.H. Liu, B. Philip, S. Gomez, W.R. Burns, V. Ramachandran, H. Wang, Z. Cruz-Monserrate, C.D. Logsdon, Cell surface lactate receptor GPR81 is crucial for cancer cell survival, Cancer Res 74 (2014) 5301-5310.

[87] C.R. Rose, A. Verkhratsky, Principles of sodium homeostasis and sodium signalling in astroglia, Glia 64 (2016) 1611-1627.

[88] D. Ruzek, L. Bell-Sakyi, J. Kopecky, L. Grubhoffer, Growth of tick-borne encephalitis virus (European subtype) in cell lines from vector and non-vector ticks, Virus Res 137 (2008) 142-146.

[89] D. Ruzek, M. Vancova, M. Tesarova, A. Ahantarig, J. Kopecky, L. Grubhoffer, Morphological changes in human neural cells following tick-borne encephalitis virus infection, J Gen Virol 90 (2009) 1649-1658.

[90] G. Sanacora, M. Banasr, From pathophysiology to novel antidepressant drugs: glial contributions to the pathology and treatment of mood disorders, Biol Psychiatry 73 (2013) 1172-1179.

[91] A. Schmitt, C. Steyskal, H.G. Bernstein, T. Schneider-Axmann, E. Parlapani, E.L. Schaeffer, W.F. Gattaz, B. Bogerts, C. Schmitz, P. Falkai, Stereologic investigation of the posterior part of the hippocampus in schizophrenia, Acta Neuropathol 117 (2009) 395-407.

[92] M. Schulz, B. Engelhardt, The circumventricular organs participate in the immunopathogenesis of experimental autoimmune encephalomyelitis, Cerebrospinal Fluid Res 2 (2005) 8.

[93] R. Schwarcz, C.A. Hunter, Toxoplasma gondii and schizophrenia: linkage through astrocyte-derived kynurenic acid?, Schizophr Bull 33 (2007) 652-653.

[94] M.D. Scofield, H. Li, B.M. Siemsen, K.L. Healey, P.K. Tran, N. Woronoff, H.A. Boger, P.W. Kalivas, K.J. Reissner, Cocaine self-administration and extinction leads to reduced glial fibrillary acidic protein expression and morphometric features of astrocytes in the nucleus accumbens core, Biol Psychiatry 80 (2016) 207-215. 
[95] S.K. Sikdar, R. Zorec, W.T. Mason, cAMP directly facilitates Ca-induced exocytosis in bovine lactotrophs, FEBS Lett 273 (1990) 150-154.

[96] M.V. Sofroniew, Astrogliosis, Cold Spring Harb Perspect Biol 7 (2014) a020420.

[97] M.V. Sofroniew, Multiple roles for astrocytes as effectors of cytokines and inflammatory mediators, Neuroscientist 20 (2014) 160-172.

[98] M. Stenovec, E. Lasic, P.P. Dominkus, S.T. Bobnar, R. Zorec, M. Lenassi, M. Kreft, Slow Release of HIV-1 Protein Nef from Vesicle-like Structures Is Inhibited by Cytosolic Calcium Elevation in Single Human Microglia, Mol Neurobiol (2018).

[99] W. Stenzel, S. Soltek, D. Schluter, M. Deckert, The intermediate filament GFAP is important for the control of experimental murine Staphylococcus aureus-induced brain abscess and Toxoplasma encephalitis, J Neuropathol Exp Neurol 63 (2004) 631-640.

[100] A.R. Styczynski, J. Malta, E.R. Krow-Lucal, J. Percio, M.E. Nobrega, A. Vargas, T.M. Lanzieri, P.L. Leite, J.E. Staples, M.X. Fischer, A.M. Powers, G.J. Chang, P.L. Burns, E.M. Borland, J.P. Ledermann, E.C. Mossel, L.B. Schonberger, E.B. Belay, J.L. Salinas, R.D. Badaro, J.J. Sejvar, G.E. Coelho, Increased rates of Guillain-Barre syndrome associated with Zika virus outbreak in the Salvador metropolitan area, Brazil, PLoS Negl Trop Dis 11 (2017) e0005869.

[101] Y. Suzuki, Q. Sa, M. Gehman, E. Ochiai, Interferon-gamma- and perforin-mediated immune responses for resistance against Toxoplasma gondii in the brain, Expert Rev Mol Med 13 (2011) e31.

[102] F. Tang, S. Lane, A. Korsak, J.F. Paton, A.V. Gourine, S. Kasparov, A.G. Teschemacher, Lactate-mediated glia-neuronal signalling in the mammalian brain, Nat Commun 5 (2014) 3284.

[103] K. Tech, T.R. Gershon, Energy metabolism in neurodevelopment and medulloblastoma, Transl Pediatr 4 (2015) 12-19.

[104] M.G. Vander Heiden, L.C. Cantley, C.B. Thompson, Understanding the Warburg effect: the metabolic requirements of cell proliferation, Science 324 (2009) 1029-1033.

[105] N. Vardjan, H.H. Chowdhury, A. Horvat, J. Velebit, M. Malnar, M. Muhic, M. Kreft, S.G. Krivec, S.T. Bobnar, K. Mis, S. Pirkmajer, S. Offermanns, G. Henriksen, J. Storm-Mathisen, L.H. Bergersen, R. Zorec, Enhancement of Astroglial Aerobic Glycolysis by Extracellular Lactate-Mediated Increase in CAMP, Front Mol Neurosci 11 (2018) 148.

[106] N. Vardjan, A. Verkhratsky, R. Zorec, Pathologic potential of astrocytic vesicle traffic: new targets to treat neurologic diseases?, Cell Transplant 24 (2015) 599-612.

[107] N. Vardjan, R. Zorec, Excitable Astrocytes: $\mathrm{Ca}^{2+}$ - and cAMP-Regulated Exocytosis, Neurochem Res 40 (2015) 2414-2424. 
[108] A. Verkhratsky, A. Marutle, J.J. Rodriguez-Arellano, A. Nordberg, Glial asthenia and functional paralysis: A new perspective on neurodegeneration and Alzheimer's disease, Neuroscientist 21 (2015) 552-568.

[109] A. Verkhratsky, M. Matteoli, V. Parpura, J.P. Mothet, R. Zorec, Astrocytes as secretory cells of the central nervous system: idiosyncrasies of vesicular secretion, EMBO J 35 (2016) 239-257.

[110] A. Verkhratsky, M. Nedergaard, Astroglial cradle in the life of the synapse, Philos Trans R Soc Lond B Biol Sci 369 (2014) 20130595.

[111] A. Verkhratsky, M. Nedergaard, The homeostatic astroglia emerges from evolutionary specialization of neural cells, Philos Trans R Soc Lond B Biol Sci 371 (2016).

[112] A. Verkhratsky, M. Nedergaard, Physiology of astroglia, Physiol Rev 98 (2018) 239-389.

[113] A. Verkhratsky, N.A. Oberheim Bush, M. Nedergaard, A. Butt, The Special Case of Human Astrocytes, Neuroglia 1 (2018) 4.

[114] A. Verkhratsky, M. Olabarria, H.N. Noristani, C.Y. Yeh, J.J. Rodriguez, Astrocytes in Alzheimer's disease, Neurotherapeutics 7 (2010) 399-412.

[115] A. Verkhratsky, V. Parpura, Astrogliopathology in neurological, neurodevelopmental and psychiatric disorders, Neurobiol Dis 85 (2016) 254-261.

[116] A. Verkhratsky, J.J. Rodriguez, V. Parpura, Astroglia in neurological diseases, Future Neurol 8 (2013) 149-158.

[117] A. Verkhratsky, J.J. Rodriguez, L. Steardo, Astrogliopathology: a central element of neuropsychiatric diseases?, Neuroscientist 20 (2014) 576-588.

[118] A. Verkhratsky, L. Steardo, V. Parpura, V. Montana, Translational potential of astrocytes in brain disorders, Prog Neurobiol 144 (2016) 188-205.

[119] A. Verkhratsky, R. Zorec, V. Parpura, Stratification of astrocytes in healthy and diseased brain, Brain Pathol 27 (2017) 629-644.

[120] A. Verkhratsky, R. Zorec, J.J. Rodriguez, V. Parpura, Astroglia dynamics in ageing and Alzheimer's disease, Curr Opin Pharmacol 26 (2016) 74-79.

[121] E.H. Wilson, C.A. Hunter, The role of astrocytes in the immunopathogenesis of toxoplasmic encephalitis, Int J Parasitol 34 (2004) 543-548.

[122] J.L. Zamanian, L. Xu, L.C. Foo, N. Nouri, L. Zhou, R.G. Giffard, B.A. Barres, Genomic analysis of reactive astrogliosis, J Neurosci 32 (2012) 6391-6410.

[123] R. Zorec, V. Parpura, A. Verkhratsky, Astroglial vesicular network: evolutionary trends, physiology and pathophysiology, Acta Physiol (Oxf) 222 (2018). 
Figure 1. Electron micrograph of Zika virus (strain Uganda 976) in an infected Vero cell; ultrathin section was stained with $0,5 \%$ uranyl acetate. Imaging of the ultrathin section was performed with use of 120-kV JEM-1400 Plus electron microscope (JEOL); magnification 40.000x (horizontal bar represents $200 \mathrm{~nm}$ ). Photomicrograph was kindly provided by Dr. M. Poljšak Prijatelj and Mr. M. Kolenc (Intitute of Microbiology and Immunology, Medical Faculty, University of Ljubljana).

Figure 2. Time-dependence of the number of endosomes and lysosomes associated with fluorescently labelled TBEV particles in astrocytes.

(Ai,ii). An astrocyte with DiD-labelled TBEV vesicles (TBEV) incubated at $37 \stackrel{\circ}{\circ}$ for $4 \mathrm{~h}$ and $18 \mathrm{~h}$ and with labelled early endosomes (EEA1) Overlays represents overlapped TBEV and EEA1 fluorescent signals, indicating the association between TBEV and endosomes. Bars: $5 \mu \mathrm{m}$. (Aiii) Prolonged incubation increased the average number of TBEV labelled vesicles per cell and also the average number of vesicles co-labelled with TBEV and EEA1. Black bars - TBEV labelled vesicles, white bars - TBEV and EEA1 co-labelled vesicles, ${ }^{*} P<0.05$. (Bi,ii) An astrocyte with DiD-labelled TBEV vesicles (TBEV) incubated at $37 \circ \mathrm{C}$ for $4 \mathrm{~h}$ and $18 \mathrm{~h}$ and with LAMP1-labelled lysosomes (LAMP1-lysosomal associated membrane protein 1). Overlays represent overlapped TBEV and LAMP1 fluorescent signals, indicating the association between TBEV and lysosomes. Bars: $5 \mu \mathrm{m}$. (Biii) Prolonged incubation increased the average number of TBEV labelled vesicles per cell and the average number of vesicles co-labelled with TBEV and LAMP1. Black bars - TBEV labelled vesicles, white bars - TBEV and LAMP1 co-labelled vesicles, ${ }^{* * *} P<0.001$. (C) Astrocyte co-labelled with antiLAMP1 and anti-EEA1. In a single, $1 \mu \mathrm{m}$ thick optical slice, lysosomes and early endosomes appear to be largely different in size due to different position in z-axis and variable antibody attachments. Arrowheads point to large late lysosomes (LAMP1) and early endosomes (EEA1). Bar (bar inset): $5 \mu \mathrm{m}(2.5 \mu \mathrm{m}) . \mathrm{n}(\mathrm{n})=$ number of cells (number of vesicles). Reprinted with permission [78].

Figure 3. Infectious agents may enter the central nervous system through two main routes: the blood (left panel) and cerebrospinal fluid (right panel). Once in the blood infectious particles may cross the endothelial cell (engaging transcytosis) or escape into the CNS parenchyma trhough fenestrae between endothelial cells. Infectious particles may enter more easily into the cerebrospinal fluid via the circumventricular organs. Right panel is a drawing of the median sagittal aspect of the human brain showing the seven circumventricular organs and choroid plexus (CP). AP, area postrema; ME, median eminence; NL, pituitary neural lobe; OVL T, organum vasculosum of the lamina terminalis; PI, pineal gland; SCO, subcommissural organ; and SFO, subfornical organ. Redrawn from [37]. 


\section{Figr-1}
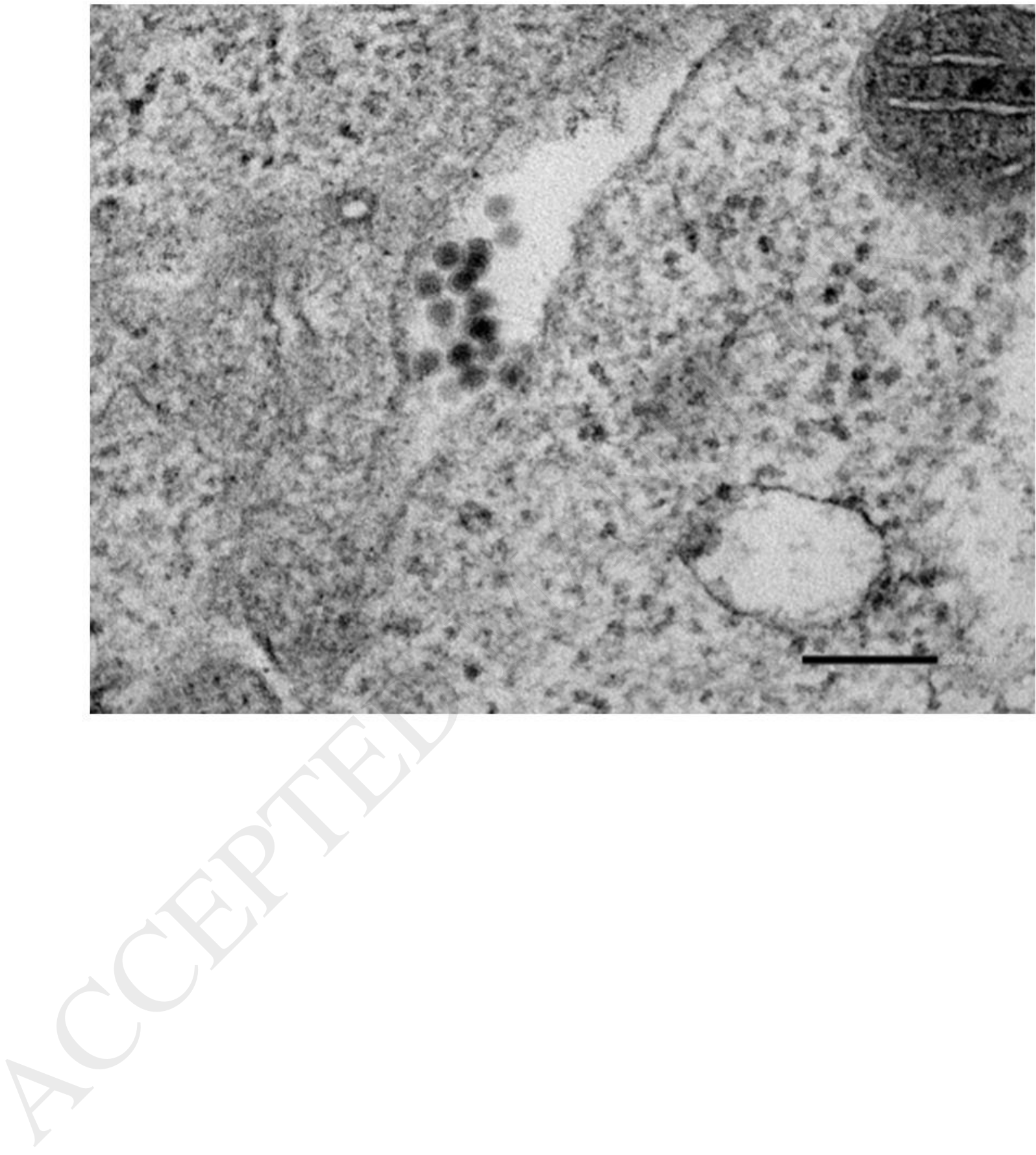
Figr-2

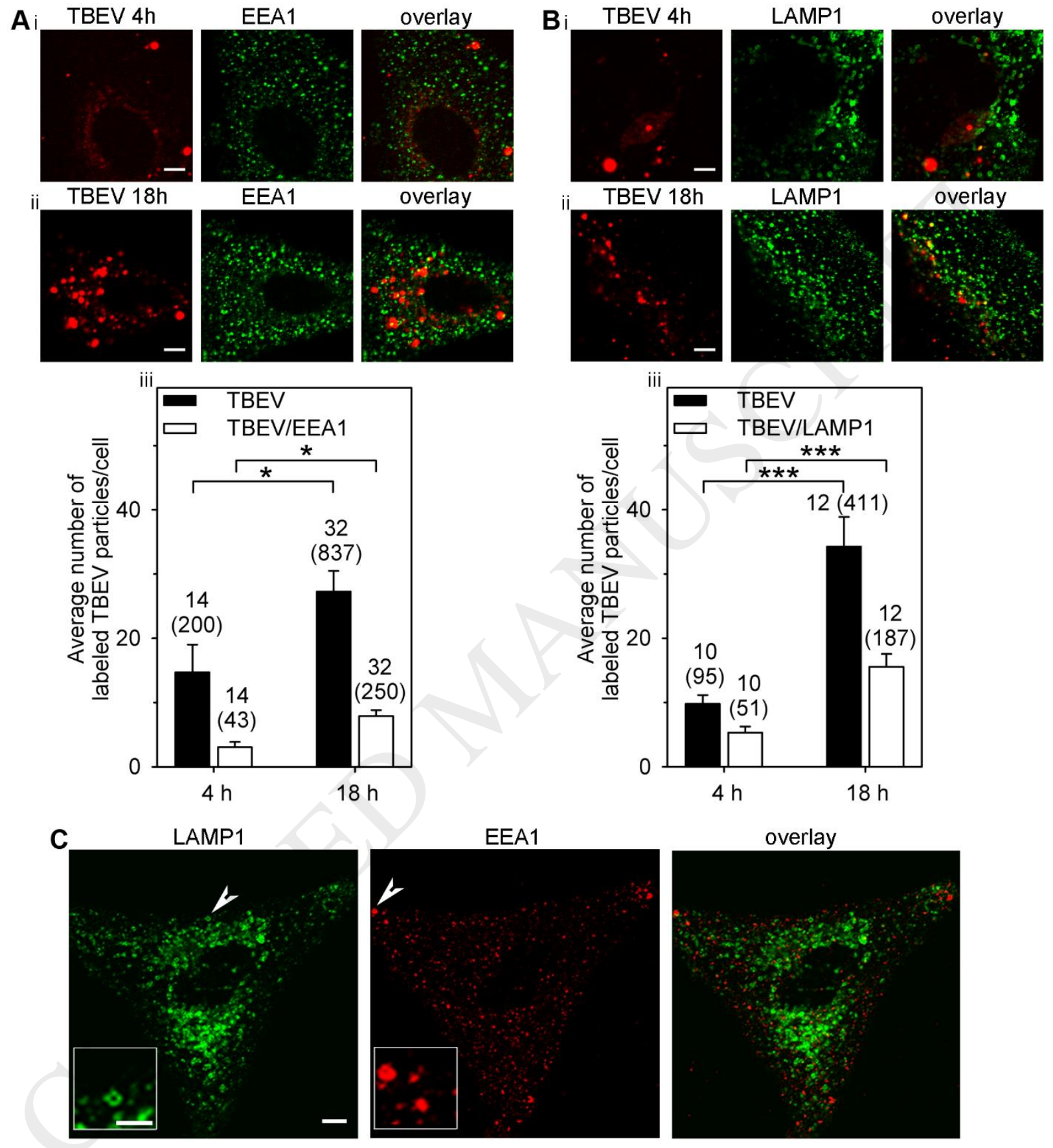


Figr-3

\section{Circumventricular organs}

of the human brain

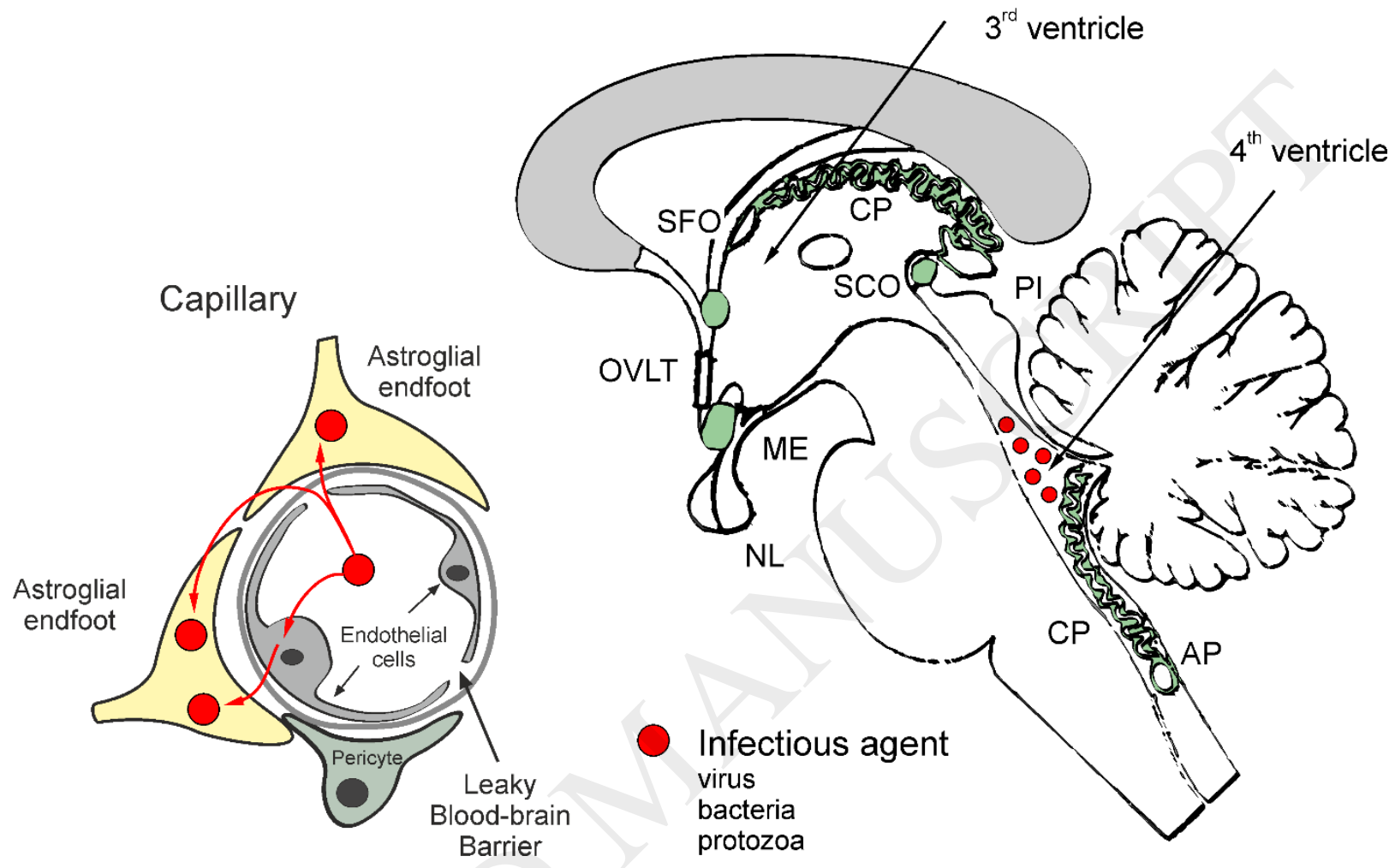

